\title{
Internet of Things (IoT) enabled water monitoring system
}

\begin{abstract}
Water is always a crucial part of everyday life. Due to global environmental situation, water management and conservation is vital for human survival. In recent times, there were huge needs of consumer based humanitarian projects that could be rapidly developed using Internet of Things (IoT) technology. In this paper, we propose an IoT based water monitoring system that measures water level in real-time. Our prototype is based on idea that the level of the water can be very important parameter when it comes to the flood occurrences especially in disaster prone areas. A water level sensor is used to detect the desired parameter, and if the water level reaches the parameter, the signal will be feed in realtime to social network like Twitter. A cloud server was configured as data repository. The measurement of the water levels are displayed in remote dashboard.
\end{abstract}

Keyword: Water monitoring; IoT; Smart home 